\title{
1 Post-growth Annealing of Bridgman-grown CdZnTe and CdMnTe Crystals \\ 2 for Room-temperature Nuclear Radiation Detectors
}

3

4 Stephen U. Egarievwe ${ }^{\mathrm{a},{ }^{*}}$, Ge Yang ${ }^{\mathrm{b}}$, Alexander A. Egarievwe ${ }^{\mathrm{a}}$, Ifechukwude O. Okwechime ${ }^{\mathrm{a}}$,

5 Justin Gray ${ }^{\mathrm{a}}$, Zaveon M. Hales ${ }^{\mathrm{a}}$, Anwar Hossain ${ }^{\mathrm{b}}$, Giuseppe S. Camarda ${ }^{\mathrm{b}}$, Aleksey E.

6 Bolotnikov ${ }^{\mathrm{b}}$, and Ralph B. James ${ }^{\mathrm{b}}$

7

${ }^{a}$ Nuclear Engineering and Radiological Science Center, Alabama A\&M University, Normal 35762, USA

$9 \quad{ }^{b}$ Nonproliferation \& National Security Department, Brookhaven National Laboratory, Upton, NY 11973, USA

\section{3}

\section{Abstract}

Bridgman-grown cadmium zinc telluride (CdZnTe or CZT) and cadmium manganese telluride (CdMnTe or CMT) crystals often have Te inclusions that limit their performances as X-ray- and gamma-raydetectors. We present here the results of post-growth thermal annealing aimed at reducing and eliminating $\mathrm{Te}$ inclusions in them. In a $2 \mathrm{D}$ analysis, we observed that the sizes of the Te inclusions declined to $92 \%$ during a 60 -hour annealing of $\mathrm{CZT}$ at $510{ }^{\circ} \mathrm{C}$ under $\mathrm{Cd}$ vapor. Further, tellurium inclusions were eliminated completely in CMT samples annealed at $570{ }^{\circ} \mathrm{C}$ in $\mathrm{Cd}$ vapor for 26 hours, whilst their electrical resistivity fell by an order of $10^{2}$. During the temperature-gradient annealing of $\mathrm{CMT}$ at $730{ }^{\circ} \mathrm{C}$ and an $18{ }^{\circ} \mathrm{C} / \mathrm{cm}$ temperature gradient for 18 hours in a vacuum of $10^{-5} \mathrm{mbar}$, we observed the diffusion of Te from the sample, so causing a reduction in size of the Te inclusions. For CZT samples annealed at $700{ }^{\circ} \mathrm{C}$ in a $10{ }^{\circ} \mathrm{C} / \mathrm{cm}$ temperature gradient, we observed the migration of Te inclusions from a low-temperature region to a high one at $0.022 \mu \mathrm{m} / \mathrm{s}$. During the temperature-gradient annealing of CZT in a vacuum of $10^{-5} \mathrm{mbar}$ at $570{ }^{\circ} \mathrm{C}$ and $30{ }^{\circ} \mathrm{C} / \mathrm{cm}$ for 18 hours, some Te inclusions moved toward the hightemperature side of the wafer, while other inclusions of the same size, i.e., $10 \mu \mathrm{m}$ in diameter, remained in the same position. These results show that the migration, diffusion, and reaction of $\mathrm{Te}$ with $\mathrm{Cd}$ in the matrix of CZT- and CMT- wafers are complex phenomena that depend on the conditions in local regions, such as composition and structure, as well as on the annealing conditions.

Keywords: CdZnTe and CdMnTe, Nuclear radiation detectors, Te inclusions, Thermal annealing in Cd vapor, Te diffusion and migration, Temperature gradient annealing 


\section{Introduction}

Cadmium zinc telluride (CdZnTe or CZT) and cadmium manganese telluride (CdMnTe or CMT) are some of the semiconductor materials that have proven to be good candidates for applications as roomtemperature nuclear-radiation detectors [1-4]. CZT has found usages in medical imaging [5] and in astrophysics for measuring celestial gamma-ray photons [6]. Bridgman-grown CZT and CMT crystals often contain Te inclusions that limit their performances as X-ray- and gamma-ray-detectors [7]. These Te inclusions form from the evaporation of $\mathrm{Cd}$ (due to the high pressure), and the deposition of segregated Te from the decomposition of the melt. Te inclusions were observed to act as localized centers where different impurities gather, and may affect electrical compensation and cause charge trapping [8]. The trapping of charge carriers generated by ionizing radiation entails fluctuations of the collected charges, so degrading the energy resolution of thick (> 5-15 mm) detectors $[9,10]$. While efforts have been made to control the formation of Te inclusions in Bridgman-grown CZT and CMT, their presence persists because the crystals are grown in Te-rich environments to ensure the high resistivity needed for the detector's room-temperature operation. Post-growth thermal annealing is a reasonable alternative to removing these performance-limiting Te inclusions.

There are two basic approaches to the post-growth thermal annealing of CZT- and CMT-crystals. The first one involves annealing the material at elevated temperatures in a Cd-rich atmosphere. Then, $\mathrm{Cd}$ diffuses within the sample and reacts with the excess Te, so replacing the Te-rich particles with crystalline material. The strain introduced by forming new CZT in place of Te particles may increase the number of dislocations in the material. This procedure also reduces the material's resistivity. Reportedly, annealing in a combination of $\mathrm{Cd}$-rich and $\mathrm{Zn}$-rich atmospheres maintains high resistivity [11]. The second thermal-annealing approach involves inducing movement of the Te inclusions under temperature gradients and their accumulation at the sample's high-temperature side, leaving the higher-quality regions of the crystal with fewer smaller particles.

In previous experiments we recorded that annealing in a $\mathrm{Cd}$ vapor effectively removes Te inclusions from CZT, and there was migration of Te inclusions for annealing in a temperature-gradient field [12]. While many of the small-size Te inclusions were eliminated after annealing in a Cd vapor at $923 \mathrm{~K}$ for 24 hours, the lager inclusions remained; and the size-reduction for larger inclusions become possible in two cases: 1) annealing at higher temperature of $1100 \mathrm{~K}$ for a shorter time of 60 minutes, and, 2) a two-cycle annealing at $1100 \mathrm{~K}$ for 15 minutes per cycle [12]. It has been reported that annealing under a Cd vapor pressure at high temperatures above $\sim 1170 \mathrm{~K}$ generates a large quantity of irregular Cd inclusions in the 
68 CZT matrix [13]. Thus, depending on the crystal composition and structure, annealing at lower 69 temperatures and longer time could have the advantage of less heat stress on the CZT matrix 70 compared to annealing at high temperatures. In the present work, we show that both elimination of 71 small-size Te inclusions and the size-reduction of large Te inclusions in CZT wafers can also be

72 achieved at lower temperature and longer time of up to 60 hours. We also present further results of 73 post-growth annealing of CZT- and CMT- crystals under Cd vapor and a temperature gradient. The 74 discussion of the new results focused on 1) the Te diffusion in the detector material, 2) the reduction in 75 the size of Te inclusions, 3) the migration of Te inclusions, and, 4) the resistivity of the wafers.

\section{Experimental Procedures}

Wafers were cut from Bridgman-grown CZT- and CMT-ingots ranging from $2.5 \mathrm{~mm}$ - to $5.25 \mathrm{~mm}$ thick, $5.0 \mathrm{~mm}$ to $10.4 \mathrm{~mm}$ long, and $5.0 \mathrm{~mm}$ - to $7.6 \mathrm{~mm}$-wide. The samples were mechanically polished with 800-grit and 1200-grit silicon carbide abrasive papers, and then polished on multi-tex pads with

82 alumina powder $\left(\mathrm{Al}_{2} \mathrm{O}_{3}\right)$ of decreasing size from 3- to 0.1-microns. Each sample was sealed in a quartz 83 ampoule under vacuum of $10^{-5}$ mbar. For annealing under $\mathrm{Cd}$ vapor, we placed $\mathrm{Cd}$ at one end of the 84 ampoule and sealed it with the sample. The sealed ampoules were placed in a predetermined region of an 85 annealing furnace. In each annealing run, the location of the ampoule was determined by setting the 86 heating elements to give a furnace-temperature profile that would give the desired annealing temperature, 87 the $\mathrm{Cd}$ temperature for annealing under a $\mathrm{Cd}$ atmosphere, and a temperature gradient for temperature88 gradient annealing. Fig. 1 shows an example of the profile of the furnace's temperature used in this 89 experiment. For annealing under $\mathrm{Cd}$ vapor, the distance between the sample and the $\mathrm{Cd}$ material was 90 determined from the profile of the furnace's temperature and the desired temperatures for the sample and $91 \mathrm{Cd}$. 


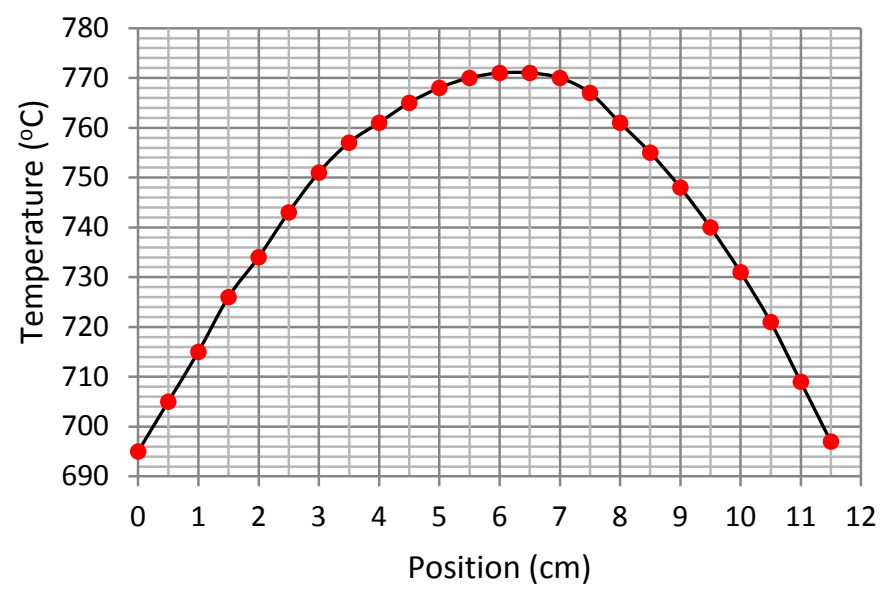

94 Fig. 1. An example of a profile of the furnace temperature used in this experiment. The top of the profile could be moved up or down to get the desired annealing-temperature and temperature-gradient.

To study diffusion of Te inclusions, the reduction in their size, and their migrations, we used infrared (IR) transmission microscopy to image them both before and after annealing; also, we then obtained the resistivity of the samples by current-voltage (I-V) measurements. The matrix of the CZT-and CMTcrystals is transparent to IR light, while the Te inclusions are opaque. The samples were marked to track

101 the locations and orientations of the Te inclusions that we studied. For I-V measurements, planar Au 102 electrical contacts were placed on two opposite surfaces of the rectangular-shaped samples by an 103 electroless chemical-deposition method, wherein $\mathrm{AuCl}_{3}$ 5\% solution droplets are pipetted on to the 104 samples' surface and the excess solution removed via a liquid-absorbing soft felt paper. The I-V 105 measurement system consists of a sample mount enclosed in an aluminum box fitted with electrical leads 106 connected to a Keithley 237 high-voltage source and a low-current measure unit.

After I-V measurements and before sealing the samples in ampoules for annealing, the Au electrical contacts were removed by polishing with a 1200-grit silicon-carbide abrasive paper, followed by 110 polishing on multi-tex pads with $\mathrm{Al}_{2} \mathrm{O}_{3}$ powder of decreasing size from 3- to 0.1- microns. Polishing was 111 repeated after annealing to remove any rough surfaces caused by heating the samples. Smoothing the 112 surface allows a more uniform entry of IR light into the matrix of the CZT and CMT-samples while 113 preventing the image of a rough surface from obscuring images of Te inclusions. The IR images were 114 taken with a Nikon industrial microscope Eclipse LV100 fitted with an IR light source, an IR camera, a 115 motorized xyz-translation stage, and image-capturing and analysis software. The following sets of 116 annealing experiments were carried out: 
1. Annealing of CZT at $510{ }^{\circ} \mathrm{C}$ under $\mathrm{Cd}$ vapor for 60 hours, after which the reduction in size of Te inclusions was measured.

2. Annealing of CMT crystals at $570{ }^{\circ} \mathrm{C}$ in $\mathrm{Cd}$ vapor for 26 hours. The elimination of Te inclusions and change in resistivity were studied.

3. Temperature-gradient annealing of CZT at $30{ }^{\circ} \mathrm{C} / \mathrm{cm}$ and $\mathrm{CMT}$ at $18{ }^{\circ} \mathrm{C} / \mathrm{cm}$ under a $10^{-5} \mathrm{mbar}$ vacuum for 18 hours at $570{ }^{\circ} \mathrm{C}$ and $730{ }^{\circ} \mathrm{C}$, respectively. This set of experiments yielded details of the diffusion and migration of Te inclusions.

4. Annealing of CZT at $700{ }^{\circ} \mathrm{C}$ under $\mathrm{Cd}$ vapor at $650{ }^{\circ} \mathrm{C}$ for 30 minutes at $10{ }^{\circ} \mathrm{C} / \mathrm{cm}$ temperature gradient. The migration of the Te inclusions under temperature gradient was measured.

\section{Results and Discussion}

The results are discussed under three categories: Thermal annealing in $\mathrm{Cd}$ vapor; annealing under a temperature gradient; and, temperature-gradient annealing in $\mathrm{Cd}$ vapor.

\subsection{Thermal Annealing in Cd Vapor}

In previous experiments we recorded that many of the small-size Te inclusions were eliminated after

134 annealing in a $\mathrm{Cd}$ vapor at $923 \mathrm{~K}\left(\sim 650{ }^{\circ} \mathrm{C}\right)$ for 24 hours while the lager inclusions remained, and 135 observed size-reduction for larger inclusions in two cases: 1) annealing at higher temperature of $1100 \mathrm{~K}$ $136\left(\sim 827^{\circ} \mathrm{C}\right)$ for a shorter time of 60 minutes, and, 2) a two-cycle annealing at $1100 \mathrm{~K}$ for 15 minutes per 137 cycle [12]. The results in the present work show that both elimination of small-size Te inclusions and 138 the size-reduction of large Te inclusions in CZT wafers can also be achieved at lower 139 temperature of $510{ }^{\circ} \mathrm{C}$ and longer time of 60 hours - see Table 1 and Fig. 2 which showed up to $14096 \%$ size reduction of large inclusions in a 2D analysis. Annealing at this relatively low 141 temperature and longer time reduces the generation of large quantity of irregular $\mathrm{Cd}$ inclusions 142 reported for annealing at much higher temperatures above $1170 \mathrm{~K}$ [13].

143 Table 1 shows the size reductions for seven selected Te inclusions in CZT annealed at $510{ }^{\circ} \mathrm{C}$ for 60 144 hours in $\mathrm{Cd}$ vapor. The areas of the Te inclusions were calculated using NIS-Elements Nikon imaging 145 software. This reduction could result from Te diffusing outside the CZT matrix, or the Te reacting with $146 \mathrm{Cd}$ that diffuses within the CZT matrix from the Cd-rich atmosphere, thus replacing the excess Te with 147 crystalline material. The dominant cause of size reduction in this case is the reaction of $\mathrm{Cd}$ with $\mathrm{Te}$ as 148 illustrated in Fig. 2 that shows the almost linear dependence of the size-reduction on the pre-annealing 
149 sizes of the Te inclusions, i.e., larger inclusions provide a larger surface area for reaction with $\mathrm{Cd}$. The 150 percent size reduction is almost constant, averaging $92 \%$.

151

152 Table 1

153 Percentage size reduction of Te inclusions in CZT annealed at $510{ }^{\circ} \mathrm{C}$ for 60 hours in Cd vapor.

\begin{tabular}{lll}
\hline Before annealing $\left(\mu \mathrm{m}^{2}\right)$ & After annealing $\left(\mu \mathrm{m}^{2}\right)$ & Size reduction $(\%)$ \\
\hline 311.2 & 24.6 & 92.1 \\
235.2 & 9.1 & 96.1 \\
359.8 & 37.4 & 89.6 \\
280.7 & 21.2 & 92.4 \\
196.1 & 29.2 & 85.1 \\
311.2 & 16.6 & 94.7 \\
333.4 & 15.9 & 95.2 \\
\hline
\end{tabular}

154

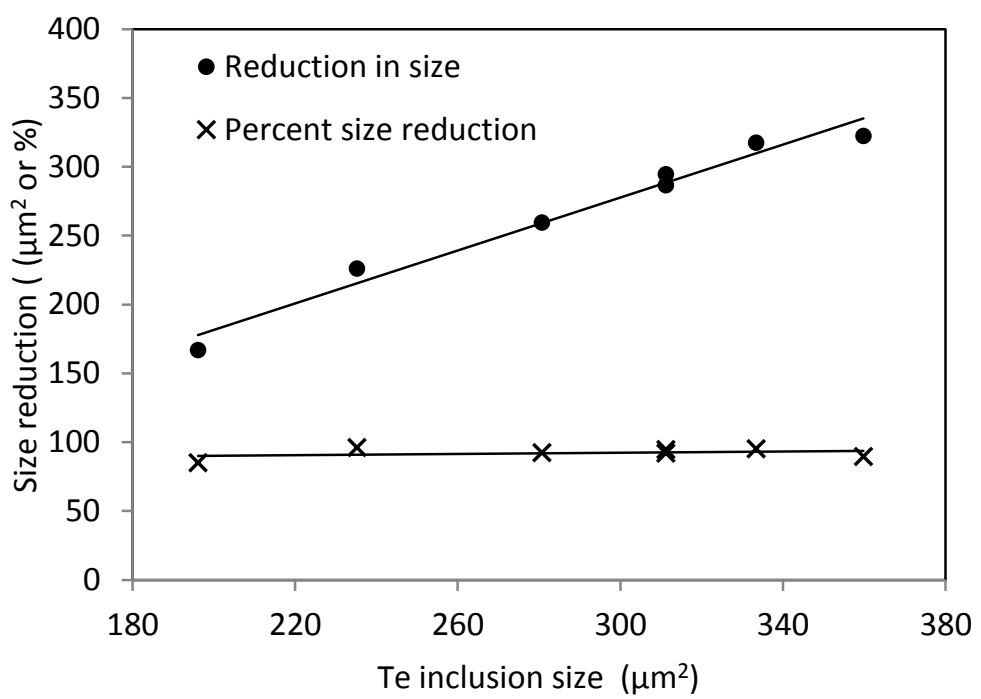

155

156 Fig. 2. Linear dependence of size-reduction on the pre-annealing sizes of the Te inclusions - larger Te

157 inclusions provide larger surface area for reacting with $\mathrm{Cd}$. The percent size reduction is approximately 158 constant.

159

160 Depending on the annealing temperature and the Cd-rich atmosphere, increasing the annealing time 161 could completely eliminate the Te inclusions. Figure 3 shows the IR images of CMT before and after 162 annealing in $570{ }^{\circ} \mathrm{C}$ in $\mathrm{Cd}$ vapor for 26 hours, at which the Te inclusions were completely eliminated 163 through the reaction of $\mathrm{Cd}$ and Te. The electrical resistivity of the CMT sample was reduced by an order 
164 of $10^{2}$, as shown by the I-V curves in Fig. 4. Similar reductions in the electrical resistivity of CZT 165 annealed in $\mathrm{Cd}$ vapor were reported in the literature, where a second step of annealing in Te-rich 166 atmosphere was used to restore the resistivity [12]. During annealing in Cd-rich atmosphere, extra Cd 167 interstitials are introduced into the CZT matrix, a process which may cause a loss of compensation 168 between deep-level Te antisites, $\mathrm{Cd}$ interstitials, and the $\mathrm{Cd}$ vacancies that are responsible for the high 169 resistivity in CdTe and its associated tertiary compounds, CdZnTe and CdMnTe [12,13]. The result is a 170 shift of the Femi level towards the bottom of the conduction band or to the top of the valence band [12]. 171 Much success was reported in increasing the resistivity of CZT by annealing in Te-rich atmosphere [14]; 172 in some cases with restoration to $10^{9} \Omega$-cm from the range of $10^{3}$ and $10^{5} \Omega-\mathrm{cm}[15]$.

173

174 Post-growth annealing processes lowered the resistivity of the CZT- and CMT-materials. This effect, 175 illustrated in Fig. 4, compares the current-voltage measurements of Bridgman-grown and modified 176 floating-zone-grown CMT crystals before and after annealing. The results of current-voltage 177 measurements on CMT wafer annealed at $570{ }^{\circ} \mathrm{C}$ in $\mathrm{Cd}$ vapor for 26 hours showed a reduction in 178 electrical resistivity by an order of $10^{2}$.

179

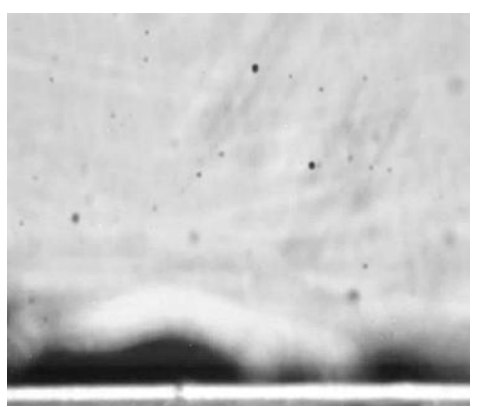

(a) Before annealing

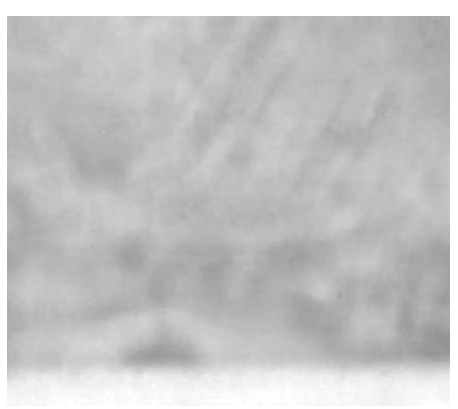

(b) After annealing

180

181 Fig. 3. Te inclusions are completely eliminated from a CMT wafer annealed at $570{ }^{\circ} \mathrm{C}$ in $\mathrm{Cd}$ vapor for 26 182 hours. 


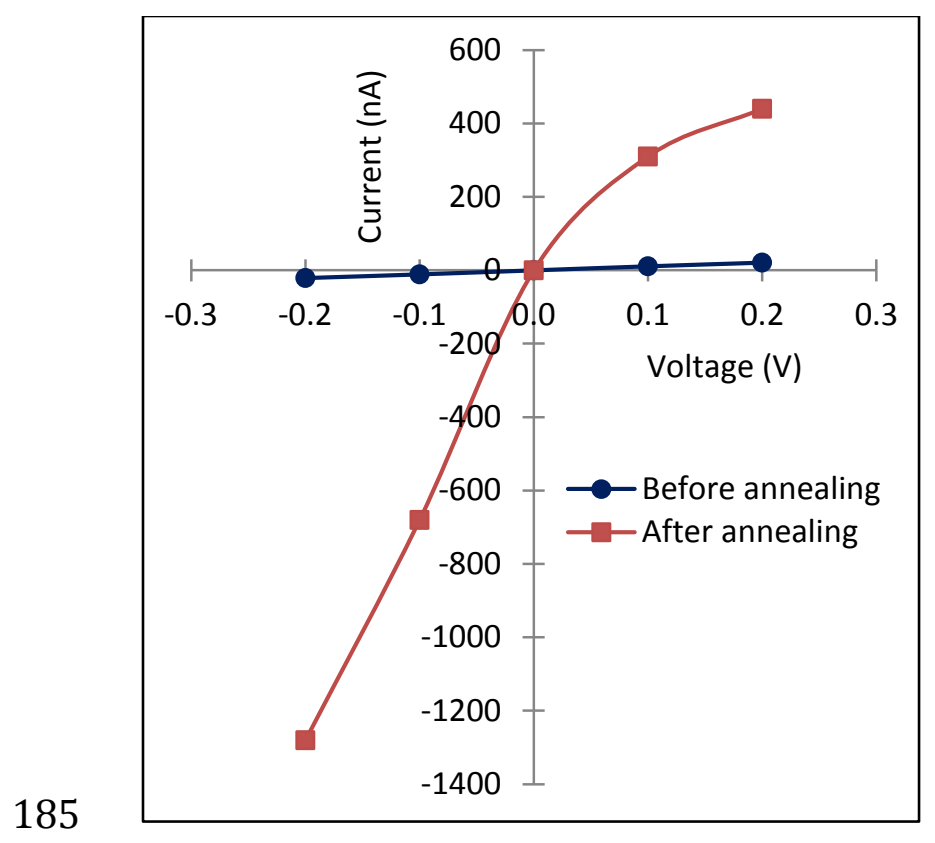

186

187 Fig. 4. I-V curve of CMT wafer annealed at $570{ }^{\circ} \mathrm{C}$ in $\mathrm{Cd}$ vapor for 26 hours, showing a reduction in 188 electrical resistivity by an order of $10^{2}$.

189

190 


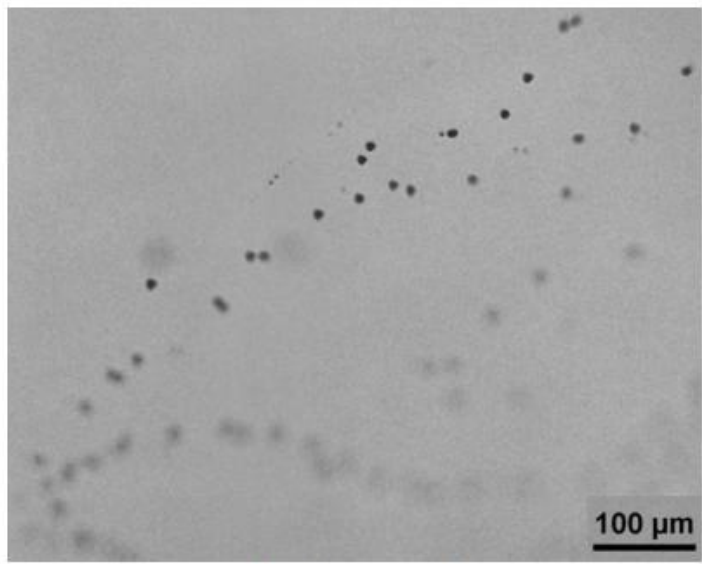

(a) Before annealing

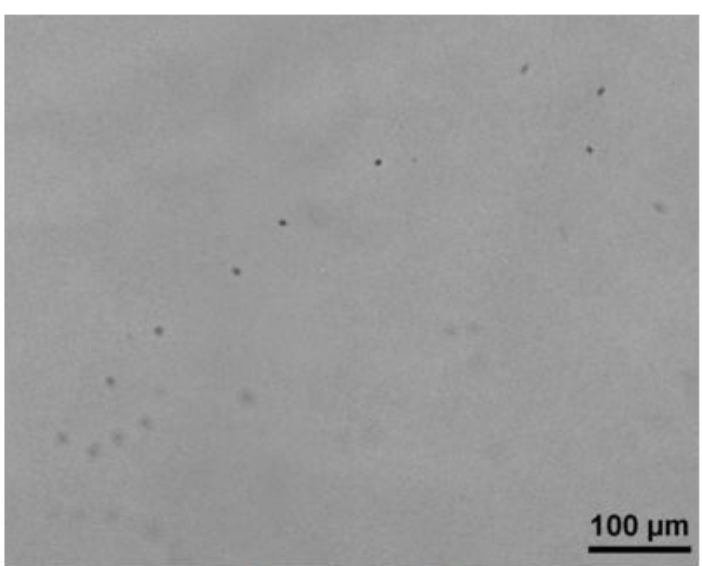

(b) After annealing

193 Fig. 5. Size reduction and elimination of Te inclusions in $2.5 \mathrm{~mm}$ x $6.9 \mathrm{~mm}$ x $7.0 \mathrm{~mm}$ CMT wafer 194 annealed at $730{ }^{\circ} \mathrm{C}$ and $18{ }^{\circ} \mathrm{C} / \mathrm{cm}$ temperature gradient for 18 hours.

\subsection{Annealing under Temperature Gradient}

199 We recorded the migration of Te inclusion under temperature gradient annealing in a Cd over 200 pressure atmosphere [12]. The present work differs in that $\mathrm{Cd}$ was not added in the ampoule to 201 anneal in $\mathrm{Cd}$ over pressure atmosphere. Thus, any $\mathrm{Cd}$ in the ampoule's atmosphere in the 202 present work would only come by diffusion from the CZT wafer and thus would create a much 203 less $\mathrm{Cd}$ atmosphere. We observed the migration, size reduction, and complete elimination of Te 204 inclusions during temperature-gradient annealing under vacuum of $10^{-5}$ mbar. The size reduction and 205 elimination of Te inclusions from some regions of the wafers, without annealing in Cd-rich atmosphere, is 
206 a significant result; it is prominent in CMT annealed at $730{ }^{\circ} \mathrm{C}$ and $18{ }^{\circ} \mathrm{C} / \mathrm{cm}$ temperature gradient for 18 207 hours (Fig. 5). This could be due to the diffusion of Te from the sample, as well as the reaction of Te 208 within the matrix during annealing. This explanation is further supported by the 2D size distribution of 209 Te inclusions, in a $2.2 \times 10^{6} \mu \mathrm{m}^{2}$ area of the CMT wafer, shown in Figure 6. The size of the CMT wafer 210 was $2.5 \mathrm{~mm} \times 6.9 \mathrm{~mm} \times 7.0 \mathrm{~mm}$, is fairly thin compared to the size of the CZT wafer, $5.2 \mathrm{~mm} \times 7.6 \mathrm{~mm} \times$ $21110.3 \mathrm{~mm}$. The IR images of the CMT and CZT wafers are shown respectively in Figs. 5 and 7. The CZT 212 wafer was annealed at $570{ }^{\circ} \mathrm{C}$, and in a $30{ }^{\circ} \mathrm{C} / \mathrm{cm}$ temperature gradient for 18 hours.

213

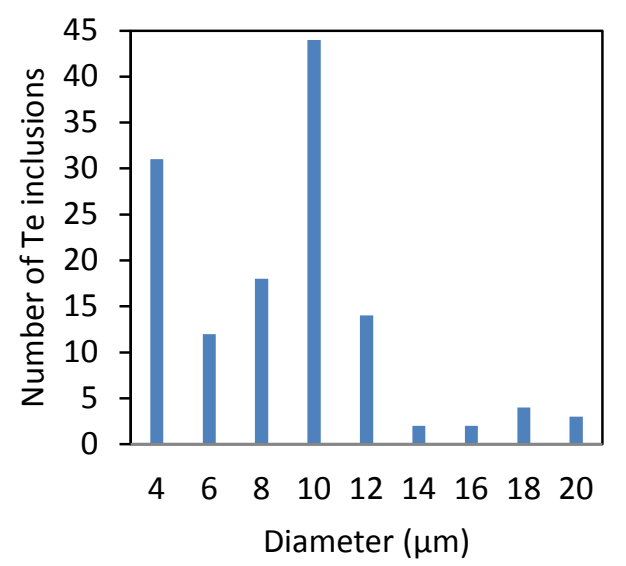

214

(a) Before annealing

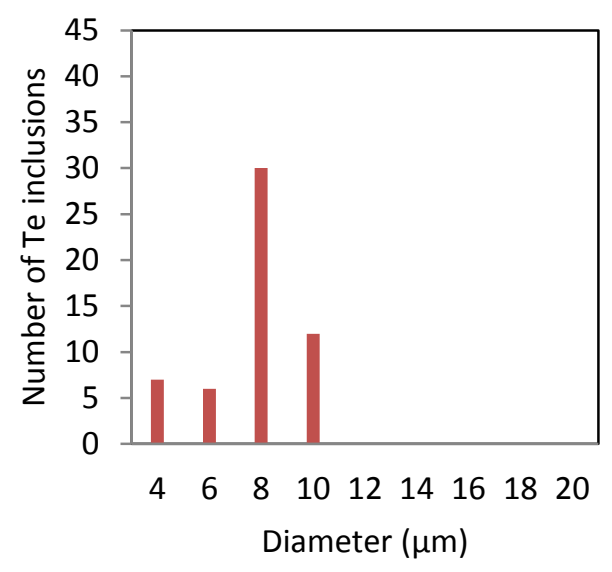

(b) After annealing

217 Fig. 6. Size distribution of Te inclusions in a $2.2 \times 10^{6} \mu \mathrm{m}^{2}$ area of a CMT wafer annealed at $730{ }^{\circ} \mathrm{C}$ and $21818{ }^{\circ} \mathrm{C} / \mathrm{cm}$ temperature gradient for 18 hours. The diameters of the Te inclusions were measured within \pm 1 $219 \mu \mathrm{m}$. 


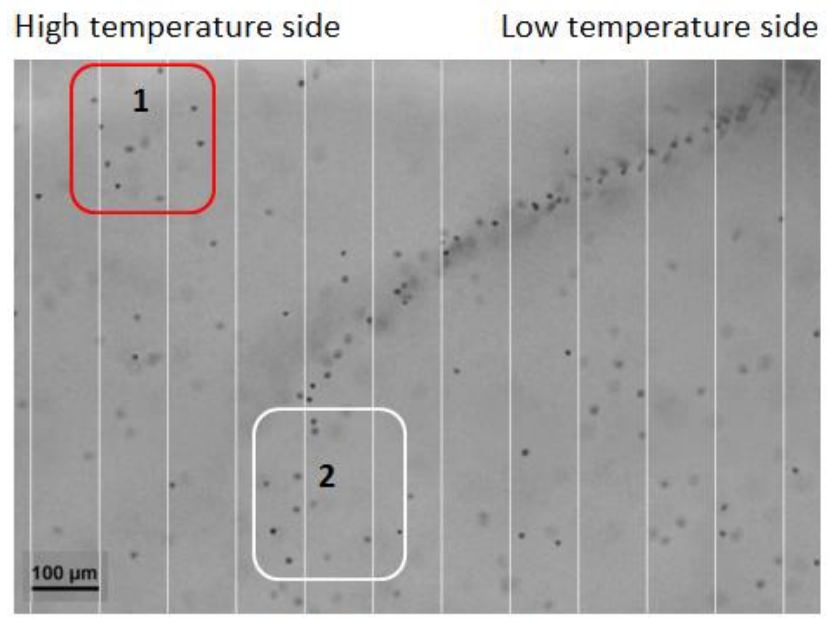

(a) Before annealing

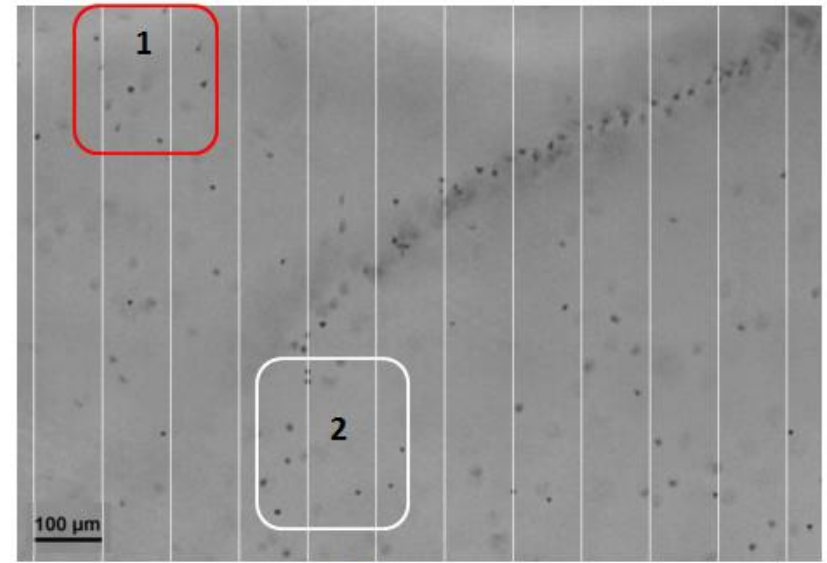

(b) After annealing

223 Fig. 7. CZT wafer size of $5.2 \mathrm{~mm} \times 7.6 \mathrm{~mm} \times 10.3 \mathrm{~mm}$ annealed at $570{ }^{\circ} \mathrm{C}$ and $30{ }^{\circ} \mathrm{C} / \mathrm{cm}$ temperature

224 gradient for 18 hours. The Te inclusions are about $10 \mu \mathrm{m}$ in diameter. Some inclusions remained in the 225 same position, while other migrated towards the wafer's high temperature side.

\subsection{Temperature-gradient Annealing in Cd Vapor}

Annealing under a temperature gradient and in Cd-rich atmosphere is expected to result in both a size 230 reduction of the Te inclusions and their migration. In previous experiments, we observed both effects 231 during the $10{ }^{\circ} \mathrm{C} / \mathrm{cm}$ temperature-gradient annealing of $\mathrm{CZT}$ at $700{ }^{\circ} \mathrm{C}$ under $\mathrm{Cd}$ vapor at $650{ }^{\circ} \mathrm{C}$ for 30 232 minutes; we also noted voids left behind by the migrating inclusions [16]. Further analysis showed that

233 the Te inclusions migrated toward the high-temperature side of the wafer at an average speed of about $2340.022 \mu \mathrm{m} / \mathrm{s}$. 


\section{Conclusions}

We experimentally studied three major types of post-growth annealing practices for CZT- and CMTcrystals for X-ray and gamma-ray detection applications: Annealing in a Cd-rich atmosphere at constant temperature, annealing in a temperature gradient, and temperature-gradient annealing in a Cd-rich atmosphere. Under 2D IR image analysis, we observed that the area of Te inclusions in CZT was reduced by about $92 \%$ after 60 -hours annealing at $510{ }^{\circ} \mathrm{C}$ under $\mathrm{Cd}$ vapor. Tellurium inclusions were eliminated completely in CMT samples annealed at $570{ }^{\circ} \mathrm{C}$ in $\mathrm{Cd}$ vapor for 26 hours, and the electrical resistivity was reduced by an order of $10^{2}$. We also recorded a significant reduction in size of Te inclusions and their elimination in a CMT wafer annealed at $730{ }^{\circ} \mathrm{C}$ and at an $18{ }^{\circ} \mathrm{C} / \mathrm{cm}$ temperature gradient for 18 hours under a vacuum of $10^{-5} \mathrm{mbar}$. Since there was no Cd-rich atmosphere, we believe this could be due to diffusion of Te from the sample, and to the reaction of Te within the matrix during annealing. For CZT samples annealed at $700{ }^{\circ} \mathrm{C}$ in a $10{ }^{\circ} \mathrm{C} / \mathrm{cm}$ temperature gradient, we observed Te inclusions migrating from a low-temperature region to a high one at a rate of $0.022 \mu \mathrm{m} / \mathrm{s}$.

Another interesting phenomenon observed for the temperature-gradient annealing of CZT in vacuum of $10^{-5} \mathrm{mbar}$ at $570{ }^{\circ} \mathrm{C}$ and $30{ }^{\circ} \mathrm{C} / \mathrm{cm}$ for 18 hours is the movement of inclusions of $10 \mathrm{um}$ in diameter towards the high-temperature side of the wafer, while other inclusions of the same size remained in the same position. These phenomena, along with complete elimination of Te inclusions from some regions of CMT during both constant-temperature annealing in $\mathrm{Cd}$ vapor and temperature-gradient annealing, highlight the complexity of Te migration, diffusion, and reaction with $\mathrm{Cd}$ in the matrix of CZT and CMT wafers. These processes depend on the conditions in local regions, such as composition and structure, as well as the annealing conditions.

\section{Acknowledgments}

This work has been supported by the U.S. Department of Homeland Security, Domestic Nuclear

263 Detection Office, under competitively awarded contract/IAA award number 2012-DN-077-ARI065-03.

264 Alabama A\&M University researchers were also supported by the U.S. Nuclear Regulatory Commission 265 through award number NRC-27-10-514, and BNL scientists received support from the U.S. Department 266 of Energy Office of Defense Nuclear Nonproliferation R\&D. These supports do not constitute an expressed or implied endorsement by the U.S. Government. 


\section{References}

[1] R. B. James, T. E. Schlesinger, J. C. Lund, M. Schieber, Semiconductors for Room Temperature Nuclear Detector Applications, vol.43, Academic Press, New York, (1995) 334.

[2] T. E. Schlesinger, J. E. Toney, H. Yoon, E. Y. Lee, B. A. Brunett, L. Franks, R. B. James, Material Science and Engineering, vol. 32, (2001) 103.

[3] S. U. Egarievwe, K.-T. Chen, A. Burger, R. B. James, and C. M. Lisse, J. X-Ray Science and Technology, vol. 6, (1996) 309.

[4] R. Rafiei, M. I. Reinhard, K. Kim, D. A. Prokopovich, D. Boardman, A. Sarbutt, G. C. Watt, A. E. Bolotnikov, L. J. Bignell, and R. B. James, EEE Trans. Nucl. Sci. NS-60 (2) (2013) 1450.

[5] Y. Eisen, A. Shor, I. Mardor, Nuclear Science Symposium Conference Record, IEEE, vol. 5 (2003) 3311.

[6] S. Del Sordo, L. Abbene, E. Caroli, A.M. Mancini, A. Zappettini, P. Ubertini, Sensors, vol. 9, (2009) 3491.

[7] A. E. Bolotnikov, S. Babalola, G. Camarda, Y. Cui, S. Egarievwe, R. Hawrami, A. Hossain, G. Yang, R. B. James, IEEE Transactions on Nuclear Science 57 (2) (2010) 910.

[8] G. Yang, A. E. Bolotnikov, Y. Cui, G. S. Camarda, A. Hossain, R. B. James, Journal of Crystal Growth 311 (2008) 99.

[9] A. E. Bolotnikov, N. Abdul-Jabber, S. Babalola, G. S. Camarda, Y. Cui, A. Hossain, E. Jackson, H. Jackson, J. James, K. T. Kohman, A. Luryi, R. B. James, IEEE Transactions on Nuclear Science 55 (2008) 2757.

[10] G. A. Carini, A. E. Bolotnikov, G. S. Camarda, G. W. Wright, L. Li, R. B. James, Applied Physics Letters 88 (2006) 143515.

[11] G. Yang, A. E. Bolotnikov, P. M. Fochuk, Y.Cui, G. S. Camarda, A. Hossain, K. H. Kim, J. Horace, B. McCall, R. Gul, O. V. Kopach, S. U. Egarievwe, R. B. James, Journal of Electronic Materials 41 (10) (2012) 2912.

[12] G. Yang, A. E. Bolotnikov, P. M. Fochuk, O. Kopach, J. Franc, E. Belas, K.H. Kim, G. S. Camarda, A. Hossain, Y. Cui, A. L. Adams, A. Radja, R. Pinder, R. B. James, Journal of Crystal Growth 379 (2013) 16.

[13] P. Fochuk, R. Grill, O. Kopach, A. E. Bolotnikov, E. Belas, M. Bugar, G. Camarda, W. Chan, Y. Cui, A. Hossain, K. H. Kim, I. Nakonechnyi, O. Panchuk, G. Yang, and R. B. James, IEEE Transactions on Nuclear Science 59 (2) (2012) 256.

[14] P. Yu, W. Jie, T. Wang, Journal of Electronic Materials 46 (2011) 3749.

[15] K. H. Kim, J. Suh, A. E. Bolotnikov, P. M. Fochuk, O. V. Kopach, G. S. Camarda, Y. Cui, A. Hossain, G. Yang, J. Hong, R. B. James, Journal of Crystal Growth 354 (2012) 62. 
304 [16] S. U. Egarievwe, A. L. Adams, M. L. Drabo, M. D. Ashford, R. Pinder, D. E. Jones, A. Kassu, W.

305 Chan, G. Yang, G. S. Camarda, A. E. Bolotnikov, R. B. James, IEEE Nuclear Science Symposium 306 and Medical Imaging Conference (NSS/MIC) Record (2012) 4226. 